\title{
Europe's evolving graduate labour markets: supply, demand, underemployment and pay
}

\author{
Francis Green *i] and Golo Henseke
}

\begin{abstract}
For most students the aspiration to gain employment in a graduate job is the main motivation for going to university. Whether they fulfil this aspiration depends considerably on national graduate labour markets. We analyse the comparative evolution of these markets across Europe over the decade leading up to 2015, focusing on supply, graduate/ high-skilled jobs, underemployment, wages, the graduate wage premium and the penalty for underemployment. The supply of tertiary graduates increased everywhere and converged, and this upward convergence is forecast to persist. In contrast the growth of graduate jobs was slower, not ubiquitous and nonconvergent. Underemployment was spreading, though at a modest rate; this rise was convergent but not ubiquitous. The rise was most substantial in Slovenia, Slovakia, the Czech Republic, Poland, Italy and Greece. Graduates' real wages trended predominantly downward, but varied a great deal between countries. The graduate wage premium declined by more than one percentage point in seven countries. Inferences are drawn for the formation of education policy, for the broader discourse on $\mathrm{HE}$, and for research on graduate futures.
\end{abstract}

Keywords: Overeducation, Wage premium, Tertiary education, Social cohesion, Convergence

JEL Classification: 123, J2, J31

\section{Introduction}

Even though other motives are important, for most students the aspiration to gain employment in a graduate job is a central motivation for going to college or university, and there is everywhere a substantive average wage premium in prospect for tertiary graduates above those with less education. Yet the medium-term future of skilled employment has become especially uncertain. After the global massification of higher education participation (Marginson 2016), the proportion of tertiary-educated labour in the world's labour forces has been rising inexorably. Graduate underemployment-also termed 'overeducation', and first posed as a risk in the United States during the 1970s (Freeman 1976) - has become a worldwide issue, especially in those many countries where governments in the 1990s and 2000s allowed higher education enrolments to expand rapidly, unconnected

\footnotetext{
*Correspondence: francis.green@ucl.ac.uk
}

UCL Institute of Education, London, UK institutionally or economically to the more steady demands of their country's labour markets (Habibi 2019). In the twenty-first century, even without an acceleration in tertiary enrolments, some have detected renewed risk in a deceleration in the demand for high-skilled labour along with the apparent maturity of ICT as a general purpose technology (Beaudry et al. 2016); others portray this maturity of ICT as a world in which managers are able to re-organise labour processes through 'digital Taylorism', deskilling and intensification of graduate labour, except for that of a minority of elite graduates trained in globally-oriented universities (Brown et al. 2004). Still others envisage a future for work dominated by Artificial Intelligence (AI) (British Academy and the Royal Society 2018). The assumption that the large majority of tertiary graduates are guaranteed high-skilled jobs appears to be no longer valid in many countries. Already, by 2011, roughly one in three university graduates of all ages were working in non-graduate jobs in many OECD countries (Green and Henseke 2016b). 
In these circumstances, while many universities and colleges have come to focus on their employability teachings, and their careers and related services, their graduates' prospects for utilising their qualifications and skills rest to a considerable extent on the uncertain trajectory of national graduate labour markets. We ask in this paper: is gaining a tertiary degree becoming, over the medium term, a less fruitful channel to success in the labour market? Unfortunately, evidence for a sufficiently broad coverage of countries to form an overview tends to be scarce. Excess supply over demand, potentially of concern to a whole generation of students, may vary sharply between countries.

Our focus is on Europe in the decade leading up to 2015 , in part owing to the availability of recent data suitable for studying graduate underemployment trends in a significant number of disparate countries with distinctive education systems and labour markets. Europe is also of interest because of the EU's expressed objective of 'upward convergence' in several socio-economic domains, including tertiary education. Thus, an important supplementary question is whether there is evidence of convergence between national graduate labour markets: if there is convergence, a future is suggested for laggard countries; if there is persistent variation or cumulative divergence, the analysis may indicate scope for beneficial policy-learning in low-performing countries, but also provides a warning signal that the important objective of social cohesion across the European Union (Eurofound 2019) is not being achieved in this domain.

At the outset, we recognise that a graduate labour market is not expected to swiftly reach an equilibrium. The possibility that supply can diverge significantly from demand, and for long durations without significant behavioural adjustments, necessitates an examination of both graduate wages and indicators of demand alongside supply. We study the growing supplies of tertiary graduates, the evolution of high-skilled jobs and graduate underemployment (where graduates work in nongraduate jobs), and key trends in graduate wages: the average real wage, the wage premium of graduates over non-graduates, and the wage penalty suffered by graduates who become underemployed.

\section{Theories of graduate labour supply, demand, and under-employment}

We begin in this section with an overview of what existing theory and evidence tells us. From the neoclassical economic perspective, the public's desire to participate in tertiary education is in anticipation of higher pay driven by employers' demand for high skills. The state, being in full or partial control of the funding for and governance of higher education, was in many countries involved in kick-starting the massification process. Yet arguably the state has less independent influence in the era of ubiquitous mass participation; rather, from a political economy perspective the key driver is said to be middle-class, mainly urban aspirations, which are only loosely linked to economic imperatives (Marginson 2016). Eventually, most children from these socio-economic classes expect to complete higher education. With their aspirations beginning to reach satiation, the ceiling to participation could only be raised further by lifting the school achievements of more disadvantaged socio-economic groups. Yet that uplift and the necessary funding have their limits. With lagging nations catching up those ahead of the educational growth curve, we could expect "upward convergence" to emerge between nations (defined as a conventional 'beta convergence' combined with a rising average trend, for a desirable indicator). A trajectory of upward convergence of tertiary education achievement is found within Europe from 2007 onwards (Eurofound 2019 , p. 18), a dynamic which sits comfortably alongside the intended policy and systems harmonisation in the 'European Higher Education Area' that is orchestrated by the Bologna Process.

The EU's concerns, while they embrace employment, do not (at least explicitly) extend to convergence mechanisms in the availability of graduate jobs. Nevertheless, if the demand for graduate labour diverges, the differing experiences of graduates could be detrimental to a cohesive higher education area and wider cohesion objectives. Underpinning graduate labour demand is the theory of skill-biased technological change (SBTC) which characterises the predominant technologies of the modern era as leading to a proportionately increased demand for high-skilled labour. In its most recent form, SBTC has been supplemented by the 'task-based' theory of changing occupational skills demand. This theory holds that, with the development of recent technologies, many middle-level, 'routine' jobs are becoming more easily automated, displacing these employees and polarising the workforce-even while high-skilled, non-routine jobs are expanded (Autor et al. 2003; Goos et al. 2014), a process termed 'asymmetric polarisation'. With further internationalisation of production through offshoring to lower-income regions, the thinning out of middle-level jobs is extended (Blinder and Krueger 2013). These theories inhabit a global domain, with similar occupational restructuring expected in all countries open to new technologies. As these technologies are diffused, so the occupational structures-including the demand for skilled labour-would converge. And while 'high-skilled labour' is not synonymous with 'graduate labour'-indeed, graduate jobs are less prevalent in nations where there is an abundant stock of skilled non-tertiary labour (Henseke 
and Green 2017) - over time we can expect the demand for graduate labour to move in close parallel with the demand for high-skilled labour.

This universalism is challenged, however, by strategic human resource management theory, in particular the resource-based theory of the firm. In this approach, managerial cultures, industrial structures and labour market institutions are held to affect the pace and manner in which technologies are introduced (e.g. Boxall and Purcell 2011; Erez 2010; Green 2013, Chap. 5). Patterns of inter-country variation in these cultures and institutions have also been framed within production regime theory or within welfare regime theory (Gallie 2017). Added to this mix are inter-country variations in product demand structure. Empirically, the hypothesis that there has been a universal asymmetric polarisation of employment over recent decades is contested by Eurofound's jobs monitoring observatory (Eurofound 2014). In consequence, some cross-national differentiation in the trajectory of the demand for graduate labour could be expected. The trend is potentially divergent if the cumulative paths of capitalist development are sufficiently differentiated by nationally varying managerial cultures and institutions.

What happens when the aggregate supply of graduate labour diverges from demand? If supply comes to exceed the demand for graduate labour, any market-induced fall in the supply, prompted by changes in employment prospects and/or falling graduate wages, would take place over a long horizon, given the duration of the higher education investment. Only inward or outward migration of highly-educated labour could speed up the adjustment, and this too is constrained. Similarly, if employers are to respond by changing to a high-skilled production strategy, this is also likely to be over the long term. With market-induced responses set to take place over a long time frame, the expected consequence is a persistent disequilibrium, with a proportion of graduates underemployed. That proportion would increase if the growth of aggregate supply exceeds the growth in demand. As expected, evidence confirms that the prevalence of underemployment is higher where there develops a greater excess supply of graduates (Verhaest and van der Velden 2013; Green and Henseke 2016b). ${ }^{1}$

However, some part of graduate under-employment can be attributed, not so much to aggregate imbalance, as to heterogeneity among graduates. While the qualifications that underemployed graduates have gained signal a certain academic achievement, their work skills may

\footnotetext{
${ }^{1}$ In principle, if a country's institutions for matching graduate labour to graduate jobs deteriorated, one could expect a long-term increase in educational mismatches. There are, however, as yet no documented examples of this.
}

be lower than those working in graduate jobs (Green and McIntosh 2007). Nevertheless, skill heterogeneity accounts for a relatively small proportion of the variation in graduate underemployment between nations (Green and Henseke 2016b). For the most part, underemployment for newly qualified graduates signals an underutilisation of their skills. Moreover, underemployment matters and is non-trivial for both individuals and society. Underemployed graduates have substantially lower wages than their fellow graduates who have obtained graduate jobs, even though they typically receive higher wages than their work peers who have lower education (Iriondo and Pérez-Amaral 2016); they are also more likely to be dissatisfied with their work (Allen and van der Velden 2001). Once scarred by being underemployed (their further skills development being thus inhibited), it is hard to break out into graduate employment: underemployment is individually persistent (Baert et al. 2013; Kiersztyn 2013; Meroni and Vera-Toscano 2017). The possibility of underemployment increases the risks for young people undertaking an investment in higher education, and (unless we factor in the wider educational value of a university life) there is a potential waste of society's educational resources.

At any time in a complex economy, a certain minimum proportion of graduates will be under-employeda consequence of mismatches in the labour market, or restrictions on labour mobility. Some are more likely to experience underemployment than others-the probability depends, for example, on an individual's spatial mobility (Jauhiainen 2011). Since there is no consensus on a single best way of classifying underemployment one cannot easily determine what national rate of underemployment would be high enough to raise policy issues. By contrast, concern is certainly warranted where there is an increasing rate of underemployment since, as noted above, such a rise could be a sign of rising imbalance in the aggregate between supply and demand for graduate labour.

Whether graduate underemployment is rising, in the context of HE massification and potentially divergent graduate labour demand, is an empirical issue, as is the question of whether there is a divergence in the experience of under-employment among European nations. Spells of increasing graduate underemployment have been documented, but only for a few countries for irregular intervals: in Germany, Poland and Sweden during the 1990s, in Poland again between 2006 and 2016, and in the UK between 1992 and 2006 (Rohrbach-Schmidt and Tiemann 2011; Kiersztyn 2013; Korpi and Tåhlin 2009; Green 2013, p. 131; Baran 2019). By contrast, graduate underemployment fell in Germany between 1999 and 2012, especially among women (Henseke 2019). 
While tracking overall graduate labour supply, labour demand and disequilibrium will reveal much of what matters for graduates' prospects, it needs to be complemented by the trend in graduates' wages. We might expect rising graduate wages on average, given the positive economic growth experienced by most countries and the presumption of a developing knowledge economy. However, the intervention of the financial crisis in 2008-9, subsequent slow growth in many countries, and the long-term decline in labour's share of GDP (ILO and OECD 2015) could be expected to be reflected in lower graduate wages.

Also informative is the evolution of the graduate wage premium, the difference between graduates' wages and those educated to the next level down, that is, upper secondary. The graduate wage premium is typically seen as the bellwether for the prospective student evaluating the potential gains from a financial investment in higher education. Whether this premium will rise or fall will depend on the relative states of the labour markets for graduate labour and less skilled labour. Underemployed graduates typically work at one level down the skill hierarchy, displacing some of those educated to upper secondary level who in turn are obliged to take up lower-paid jobs. Thus, rising underemployment of graduates is not necessarily accompanied by a downward adjustment of the wage premium, if the average wages of those with upper secondary education fall as far or further than those of graduates. Moreover, relative wages may be 'sticky' (slow to adjust), even in flexible employment regimes. According to recent studies, while for some countries the graduate wage premium remained high or even increased during the 1990s and beyond, the premium notably fell for significant spells in Poland, Portugal, Italy, Taiwan (Strawinski et al. 2018; Figueiredo et al. 2013; Crivellaro 2016; Almeida et al. 2017; Huang and Huang 2015). Again, this evidence is patchy.

Finally, the incentive to participate in tertiary education is affected not only by the expected trajectories of the average graduate wage, but also its distribution: risk averse students will have an incentive to choose paths with lower average-yet less uncertain-rewards, such as high-level apprenticeships. Several papers have documented increasing differentiation among graduates along various domains: the subjects taken, grades achieved, or level reached; some of this dispersion is manifested through variation in occupational attainment, and in particular through underemployment because of the wage penalty that attaches to it (Martins and Pereira 2004; Hoekstra 2009; Green and Zhu 2010; Green and Henseke 2016a; Altonji et al. 2012; Figueiredo et al. 2013; Lindley and Machin 2014).
Given that there is, therefore, only a piecemeal scattering of evidence about how modern graduate labour markets have evolved, we pose the following specific questions, with the focus on Europe and the wider concerns with social cohesion within the European Union (Eurofound 2009):

i. Are the recent graduate labour supply trends universally positive, and also convergent among Europe's countries?

ii. Is the share of graduate jobs increasing universally, and also convergent among nations?

iii. Is there a predominant or universal and convergent trend towards increasing graduate under-employment?

iv. Have graduates' wages been growing or falling?

v. Has the graduate wage premium been rising or falling?

vi. Has the wage penalty from being underemployed been increasing?

\section{Data and measurement}

To answer our questions, data is required on graduate jobs, educational attainment, and the wages of graduates and less-educated workers across European countries. We focus on the period 2005 to 2015, for which we have data available in a consistent series. ${ }^{2}$ These are the microdata from the European Labour Force Survey (EU-LFS) and from the EU-Statistics on Income and Living Conditions (EU-SILC) instrument. ${ }^{3}$ We use the EU-LFS to trace changes within 26 European countries in the supply of tertiary-educated labour and the occupational position of graduates in the labour force. We focus on tertiary education, whether taught at universities or other higher education institutions. Until 2013, in official statistics tertiary education comprised levels 5 and 6 of the International Standard Classification of Education (ISCED) 1997. From 2014, ISCED-11 levels 5-8 define tertiary education in international statistics.

A key measurement issue concerns the concept and classification of 'graduate jobs'. Borrowing from our earlier theoretical and empirical work (Henseke and Green 2017), we take the concept of a graduate job to be one where most of the skills used are usually acquired in the course of tertiary education, including many of the activities surrounding it, and in the course of ensuing or

\footnotetext{
${ }^{2}$ We include all countries in the EU by 2005 who contributed data over the decade, plus Switzerland and Norway.

${ }^{3}$ https://ec.europa.eu/eurostat/statistics-explained/index.php/Living_ conditions.
} 
Table 1 Descriptive statistics

\begin{tabular}{|c|c|c|c|}
\hline & Mean & Standard deviation & $\begin{array}{l}\text { Inter-period/ } \\
\text { country range }\end{array}$ \\
\hline Tertiary graduate attainment share in the labour force (\%) & 28.6 & 8.8 & 33.0 \\
\hline Share of high-skilled occupations (\%) & 42.2 & 6.9 & 29.7 \\
\hline Under-employment rate among graduates (\%) & 17.9 & 7.4 & 32.5 \\
\hline Graduates' wages (PPP-adjusted monthly € earnings, 2015 prices) & 3558.4 & 1217.3 & 5662.9 \\
\hline Age $^{\mathrm{a}}$ & 41.5 & 1.5 & 6.1 \\
\hline Percentage male ${ }^{a}$ & 48.8 & 6.3 & 26.4 \\
\hline Percentage foreign born ${ }^{\mathrm{a}}$ & 12.2 & 11.0 & 55.0 \\
\hline
\end{tabular}

Europe 2005/2015

Derived from unweighted country averages

a Base is the working-age population with tertiary qualifications

coterminous periods of work. Those skills include, inter alia, cognitive skills, knowledge creation, management and planning skills, information-processing, and interpersonal skills (Allen and Van der Velden 2011; Barone and Ortiz 2011). There are two valid ways of operationalising the concept: either through job-holders reports of whether a graduate level qualification is required to get and do their job; or via task-based analysis of jobs to identify high-skill requirements, which in turn permit classifying jobs using any of three approaches: either through statistical methods using survey-based task data (Henseke and Green 2017), or via experts' detailed job title scrutiny (Figueiredo et al. 2011; Elias and Purcell 2013) or through reliance on a major-group occupational classifications such as ISCO-08 which is also expert-based. $^{4}$

Here, in addition to the need for a comparable European-wide indicator, to examine trends we need a classifier that is consistently defined over time. Only the major-group occupational classifier meets these requirements. We therefore take, as our 'graduate job' indicator, being in an occupation in one of the first three ISCO-08 major groups: Managers, Professionals and Technicians \& Associate Professionals; $;^{5}$ an alternative nomenclature for this classification is 'high-skilled job'. Comparing across methods, not all occupations in major groups 1-3 are determined to be graduate jobs using one or other of the alternative classifiers (an example is Managers in the

\footnotetext{
${ }^{4}$ We eschew the further method of identifying the required qualification level of a job as that obtained by the modal group within each occupation; this method builds on the near-tautological idea that graduate jobs are what graduates do, which we consider unsound. This method is particularly problematic when studying changing education requirements, since rising supplies of graduates then tautologically define rising graduate jobs.

${ }^{5}$ A small number of detailed jobs were reclassified into or out of these major groups in the 2011 ISCO revision; we assume these reflected upskilling or downskilling.
}

Transport industry). Nevertheless, a large majority (nine out of ten) sub-major groups within major groups 1-3 are found, using the task-based method, to be graduate/ high-skilled jobs in Britain (Green and Henseke 2016a).

We use the EUSILC instrument to compute trends in graduate wages (inflation and PPP adjusted), the graduate wage premium (relative to the wages of upper-secondary educated workers), and the graduate underemployment wage penalty. To compute the change in the tertiary graduate wage premium, using the sample of all employed workers in each country for each year, we regress the log of wages against a set of education level dummies, where the reference category is upper secondary, and including a conventional set of controls: a set of 5-year age dummies, a dummy for foreign-born, their interaction with gender, and a full set of year dummies. To compute the change in the graduate underemployment wage penalty, using the sample of all employed graduates in each country for each year we regress log wages on a dummy variable for employment in an occupation outside major groups $1-3$, plus the same controls.

Table 1 shows the basic descriptive statistics for the sample of all countries during the period of our analysis.

\section{Findings}

Figure 1a addresses our first question, surrounding supply. We focus on the labour force aged 30 to 59 , since almost all graduates would expect to have made the transition from education to work by age 30 in all countries, and 59 is below the normal retirement age in all countries. The figure depicts a familiar story: consistent with the prior massification of tertiary participation, the share of tertiary educated labour in the work force increased in all European countries, and by an average of 7.7 percentage points across all of Europe. The fastest growing tertiary educated workforce was in Malta, followed by Portugal, Austria, the Czech Republic and Poland; while 

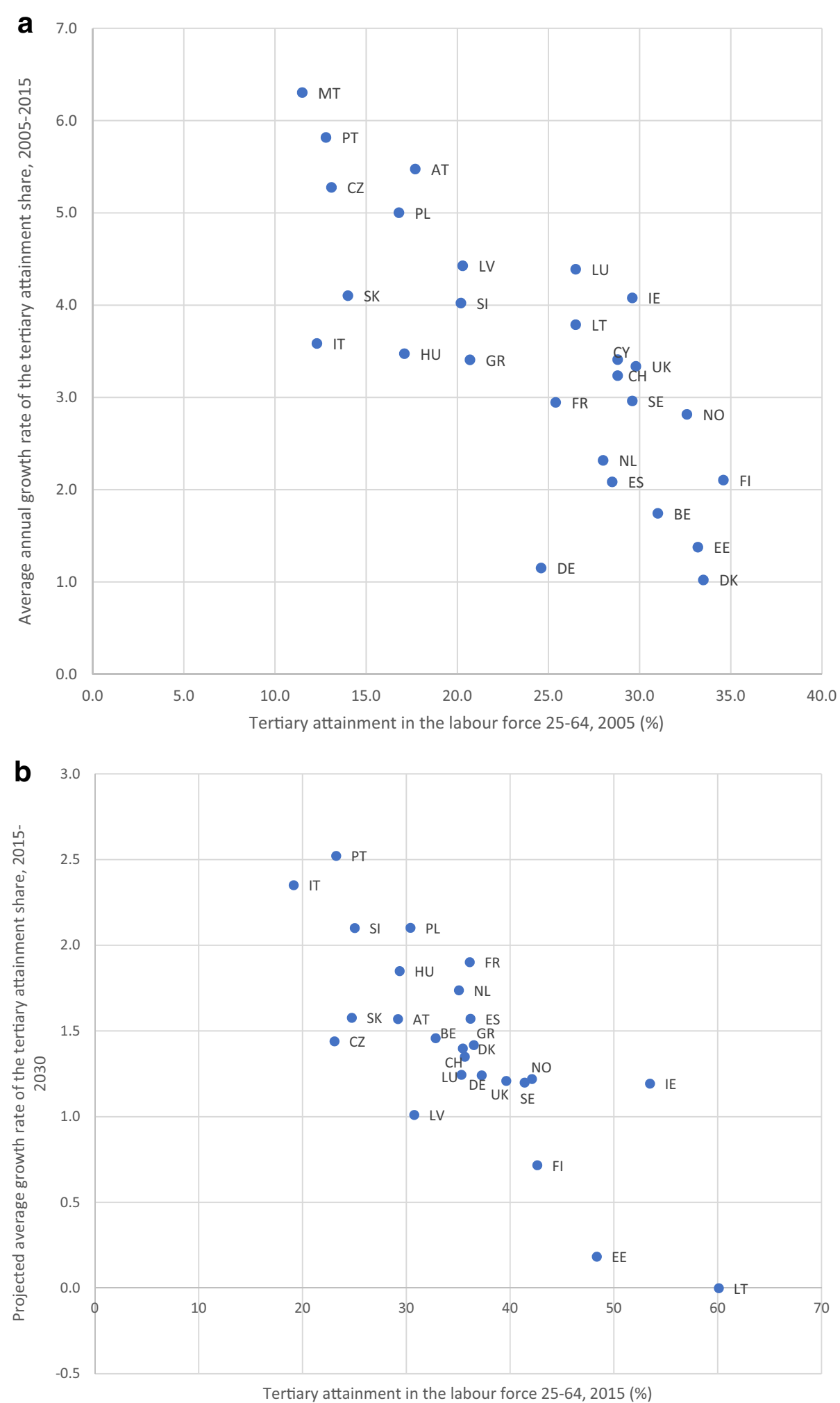

Fig. 1 a Convergence or divergence of Europe's graduate labour forces? Base: all in labour force aged 25-64. Source: European Labour Force Survey, Eurostat. Key: AT Austria, BE Belgium, CH Switzerland, CY Cyprus, CZ Czech Republic, DE Germany, DK Denmark, EE Estonia, ES Spain, FI Finland, FR France, GR Greece, HU Hungary, IE Ireland, IT Italy, LT Lithuania, LV Latvia, MT Malta, NL Netherlands, NO Norway, PL Poland, PT Portugal, SE Sweden, SI Slovenia, SK Slovak Republic, UK United Kingdom. b Convergence or divergence of the future graduate labour force? Base: working age population 25-64. Country key: see a (Data Source: Wittgenstein Centre for Demography and Global Human Capital (2019)) 


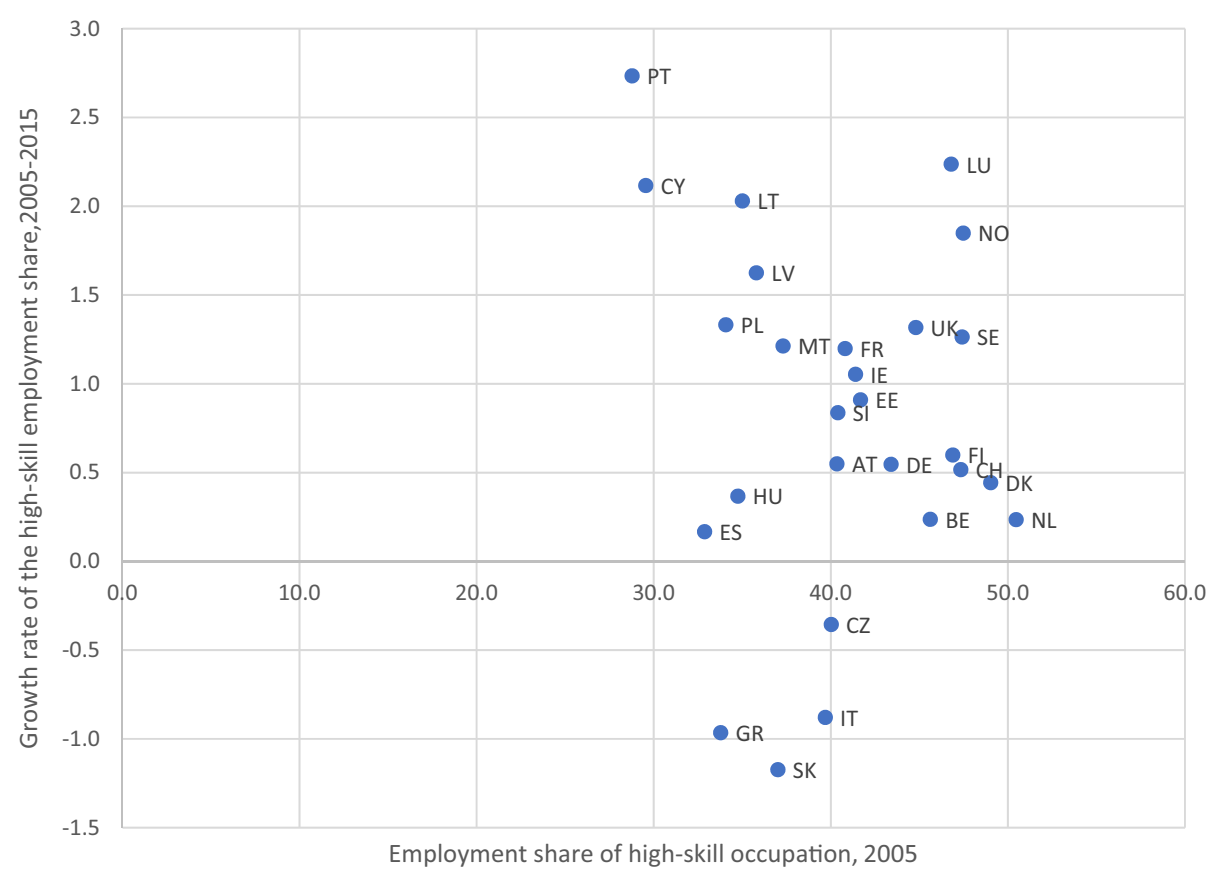

Fig. 2 Convergence or divergence of graduate jobs across Europe? Country key: see Fig. 1a (Source: European Labour Force Survey, authors' analysis)

the lowest was in Germany and Denmark. The figure, which plots these changes against the initial share in 2005, shows that the participation rate grew faster for those with initially low rates. To show this formally we ran a linear regression of the growth rate on the natural logarithm of the tertiary attainment rate in 2005: this showed Beta convergence with a coefficient of -3.02 $($ s.e. $=0.529)$. This convergence is consistent with that reported by Eurofound (2019) for a different but overlapping time interval. Together with the rising supply, our findings confirm that graduate labour supply exhibits 'upward convergence' within Europe.

\section{Can we expect upward convergence to continue in the next decade?}

Figure $1 \mathrm{~b}$ plots the projected growth in tertiary-educated labour until 2030 against the initial share in 2015. In almost every country, growth is expected to continue; this prediction would only be nullified in the wholly unlikely event of a major collapse of college participation among the present generation of young adults. Poland, Portugal, Italy, Slovenia and France are expected to have the fastest growing tertiary-educated working-age population, while continued tertiary expansion in Lithuania and Estonia may come to a halt. In all, tertiary attainment of the working age population will exceed $40 \%$ in more than two thirds of the countries in our sample by 2030, up from a quarter in 2015. Attainment is projected to continue to converge; the Beta-convergence coefficient is $-1.7(0.276)$.

Figure 2 turns to the changing share of graduate jobs/ high-skilled jobs in the workforce. It shows that the share rose over the 2005-2015 decade in most countries, the largest increase being in Portugal; yet, unlike with the graduate labour supply, this rise is not universal. In four countries (Greece, Slovakia, Italy and the Czech Republic) the share fell, while in nine other countries the rate of growth was near-zero or below one percent a year. Across Europe as a whole, the proportion of graduate jobs rose by 2.8 points to reach 42.3 percent. The plot reveals neither a convergent nor a divergent tendency: rather, whether the decade long change is positive or negative for a country is independent of the starting point for the share of graduate jobs in the employment structurecompare, for example, Greece and Portugal where the proportion of graduate jobs began at roughly the same level, then diverged remarkably, while the Netherlands' very high proportion of graduate jobs was unchanged. Formally, the Beta convergence coefficient estimate is statistically insignificant, being -0.9 (s.e. $=1.25)$.

In Fig. 3 we consider the trends in under-employment, defined here as a graduate working in an occupation classified outside the top three ISCO-08 major groups. According to this figure, under-employment was on the rise in the majority of countries, with Slovenia, Slovakia, the Czech Republic, Poland, Italy and Greece 


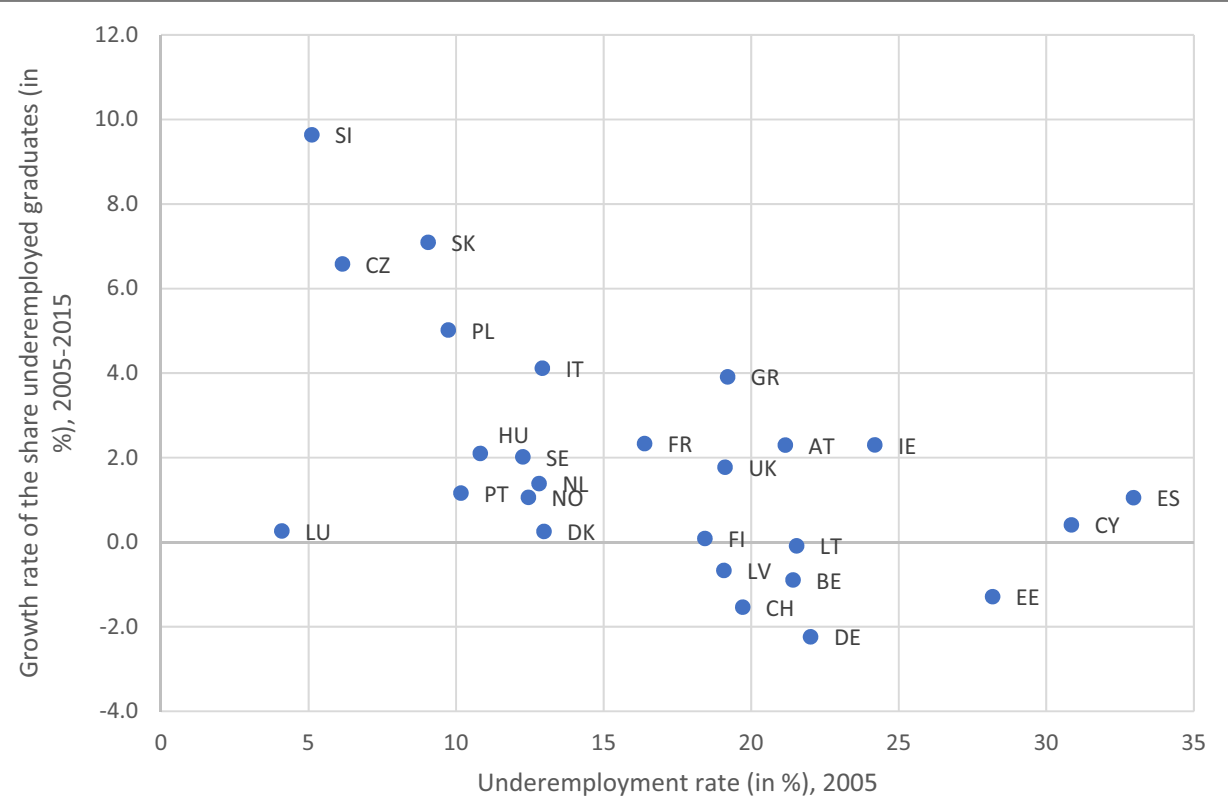

Fig. 3 Convergence or divergence in graduate under-employment? Country key: see Fig. 1a (Source: European Labour Force Survey, authors' analysis)

experiencing large increases. Yet this rise is not found everywhere: in Germany, Estonia, Switzerland and Belgium there were falls of approximately 1 percentage point or more in the proportions of graduates who were under-employed in their jobs. Taking Europe as a whole, the proportion under-employed rose only modestly, from 19 to 21 percent over the decade. The scatter plot indicates some Beta convergence, with a coefficient of -3.1 (s.e. $=0.87)$; underemployment therefore exhibits upward convergence. Visually, one can see that this convergence is driven by Slovenia, Slovakia, the Czech Republic and Poland, all of which began the period with relatively little underemployment and subsequently increased it rapidly.

Figure 4 sheds some light on these changes in underemployment, by plotting them against the change in the "relative supply" of graduates to graduate jobs (where the latter is defined as the growth rate of the tertiary attainment share minus the growth rate of the high-skilled employment rate). The figure reveals that the changing proportion of individual graduates who find themselves underemployed bears a direct positive relation to the changing relative supply. A percent change in the relative supply of graduates is associated with a 1.3 percent $(s . e=0.28)$ higher growth rate of the share of underemployed graduates. Countries at the high end of the rise in relative supply-Slovakia and the Czech Republic, notably-witnessed the largest rise in the proportion of graduates who are underemployed; while at the low end Estonia and Germany, countries with little or no change in relative supply, even experienced a decline in the proportion who were underemployed: that small decline could be accounted for by improved matching efficiency between graduates and jobs, though we offer no independent evidence for that. Referring back to Figs. 1 and 3 reveals that, in some of the cases of substantially rising underemployment (Slovenia, Poland and Austria), the proximate cause was an especially high expansion of the graduate labour force over the decade. In other places where underemployment rose fast (Greece, Slovakia and Ireland), the proximate cause was that the proportion of graduate jobs fell or barely changed over the decade. In the case of The Czech Republic, both factors were in play.

Figure 5 and onwards turn to the trends in graduate wages, which complement the picture of supply and demand trends we have so far identified. As can be seen in Fig. 5, real wages of 25-34 year-olds (after allowing for inflation) if anything predominantly trended downward over the decade: taking all European countries together, the real wage fell by approximately -0.8 percent per annum. The variation across countries is also striking. The greatest falls were seen in Greece, Portugal and the UK, while the largest annual rise (4.2 percent) was recorded in Slovakia. Among the richest countries it was the young graduates in Switzerland who fared best (1.7 percent growth). If one compares the rewards of young graduates in Switzerland with those working in the United Kingdom's, their relative fortunes changed by a remarkable 53 percent over the decade. Formally, 


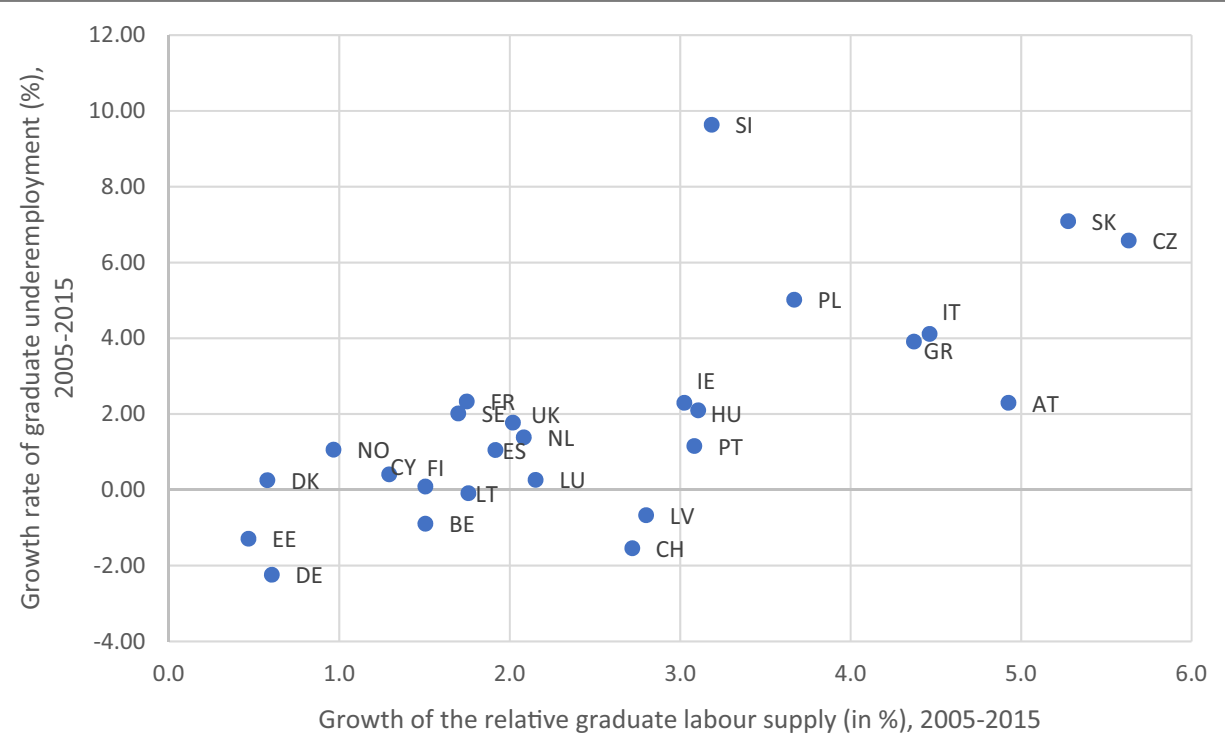

Fig. 4 Relationship of changing graduate underemployment with changes in the relative graduate labour supply. Country key: see Fig. 1a. The growth rate of the relative graduate labour supply is defines as the growth rate of tertiary attainment in the working age population net of the growth rate of the high-skill employment share (Source: ELFS, authors'analysis)

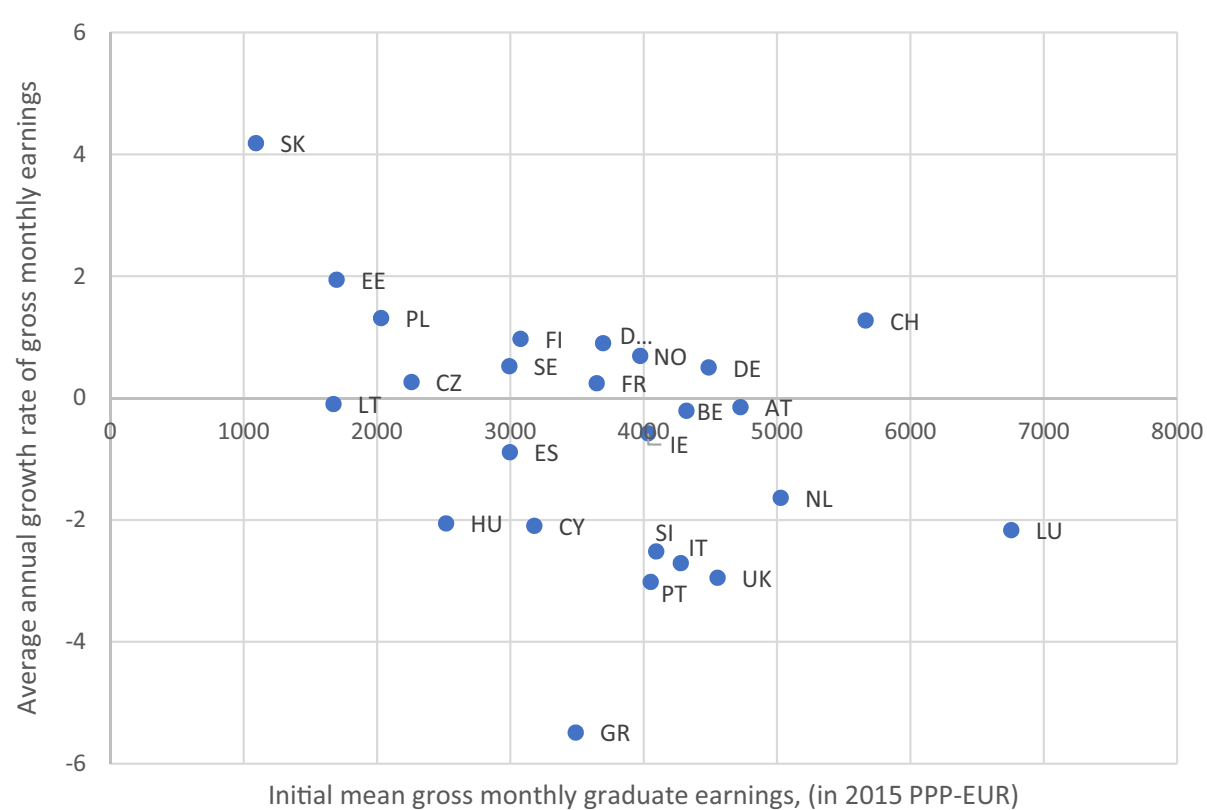

Fig. 5 Convergence or divergence in graduates' wages. Income figures deflated using Eurostat's Harmonised index of consumer prices (HICP) and converted to PPP-EUR with Purchasing Power Parity data for individual consumption across the EU-15 in 2015. The base is graduates aged 25-34. The initial income reference year varies from 2003 to 2004, with a median of 2004. The final reference year varies from 2014 to 2016 with a median of 2015. Country key: see Fig. 1a (Source: EU-SILC; authors'analysis)

graduate wages are nevertheless overall convergent, with a Beta coefficient of -2.4 (s.e. $=0.85)$.

Figure 6 shows the graduate wage premium across Europe, the comparison of the wages of graduates with those qualified to upper secondary level. It can be seen from the figure that the premium fell substantially in Lithuania, Slovenia, Portugal, Slovakia, Poland, Hungary and Greece. Five of these cases, the exceptions 


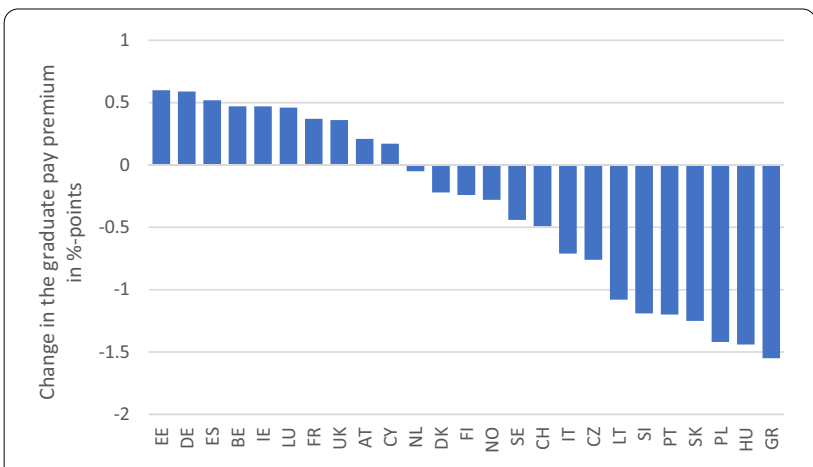

Fig. 6 The changing graduate wage premium. See notes to Figs. 1a and 5 (Source: EU-SILC; authors' analysis)

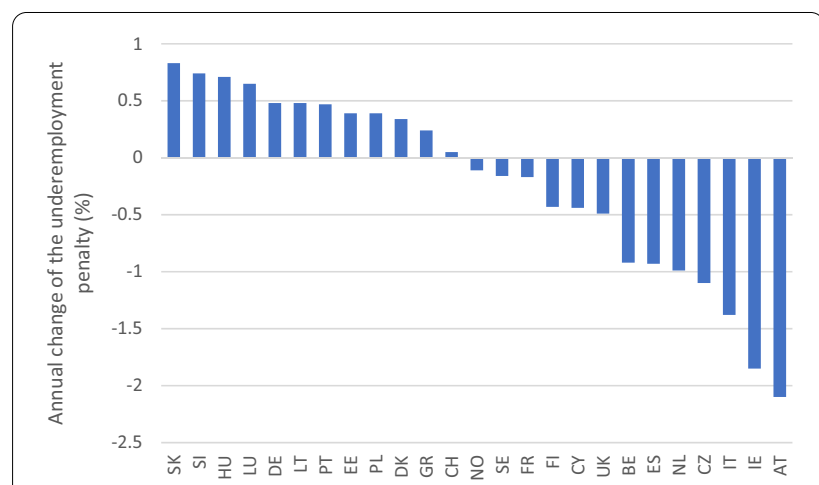

Fig. 7 Average annual change in the underemployment wage penalty. See notes to Figs. 1 a and 5 (Source: EU-SILC; authors' analysis)

being Hungary and Lithuania, showed high increases in underemployment over the period (Fig. 3). In other countries the wage premium changes were small (compared with the average level), and evenly mixed between increasing and decreasing premiums.

Finally, Fig. 7 depicts the trend in the wage penalty for being underemployed. Overall across countries, underemployed graduates earned around a third less than graduates doing graduate jobs, though this pay penalty slowly declined by 0.71 percent per year. At the extremes the underemployment wage penalty increased at a rate of more than 1.2 percentage points per annum in Slovenia and Portugal. At the other extreme the penalty fell at 1.5 percent or more in Ireland and Austria. However, with the exception of Slovenia, there is no country in the sample where a substantially rising underemployed pay penalty is compounded by a growing prevalence of underemployment.

\section{Discussion}

This paper contributes an understanding of decadelong change in European graduate labour markets. The key medium term trends, so crucial for the prospects of modern day students across Europe, may be summarised as follows. The decade leading up to 2015 saw the predicted ongoing increase in the tertiary attainment level of Europe's workforces, and there is evidence of substantive convergence. In answer to our first research question, then, we confirm Eurofound's own conclusion that the tertiary labour supply exhibits upward convergence. In parallel with, though quite disengaged from the motors of supply, there was an overall rise in the demand for graduate/high-skilled labour as defined by employment in the top three occupational major groups. However, in answer to our second question we find that the growth of demand was not ubiquitous, was overall slower than the growth of graduate supply, and was non-convergent. This conclusion is prima facie more consistent with a country-specific or a varieties of capitalism perspective, such as strategic human resource management theory, than the universalist expectation of the theory of skill-biased technological change.

Our third empirical question asked whether there has been a universal tendency for increasing tertiary labour supply to exceed the growth of demand. Consistent with our first two sets of findings, while the predominant trend is that the prevalence of underemployment has been spreading in Europe, the rise is modest; moreover, the rise was neither ubiquitous, nor convergent between countries. Where underemployment was rising especially fast, the proximate reason varied across countries: in some, the supply of tertiary graduates had risen especially fast, outstripping the changing occupational composition; in others, the rate of supply increase was no more than average but the employment of high-skilled labour was falling.

In response to our fourth question, about which we had no prior expectations, in the majority of countries graduates' real wages fell over the period. We speculate that this fall is linked to the long-term decline in the wage share of GDP in many countries coupled with slower productivity growth; the path of wages would also have been affected by the financial crisis and recession during the decade: these factors will have affected the general level of wages, including those of graduates. For the fifth question, we found that the graduate wage premium also declined in seven countries by more than one percentage point-Lithuania, Slovenia, Portugal, Slovakia, Poland, Hungary and Greece; all but the first of these exhibited rising underemployment. Finally, the wage penalty from underemployment is one manifestation of dispersion 
among graduates; however, there is no general tendency for the penalty from underemployment to increase.

Turning to the incentives facing prospective students in the medium-term future, the supply trends are easier to call than the demand trends. One might speculate whether the lower premium in Portugal, Slovenia, Greece, Hungary and Poland will lead to falling tertiary participation in these countries. For the reasons outlined by Marginson (2016) -in particular, the upward ratcheting of social and economic aspirations-falling participation is by no means certain or even likely. Even if participation were to fall or flat-line, an increasing supply of tertiary graduates in all of Europe's workforces is almost certain, given the difference between the tertiary attainments of the young and old. Estonia and Finland are possible exceptions.

The future trend of demand for graduate labour is much less certain. Extrapolation from the recent decade would be a common first estimate, on the assumption that technology and demand-driven trends are likely to persist. However, this approach may not be valid here. Some predictions suggest a future for work dominated by disruptive, machine-learning technologies that will displace skilled labour. Given the widely varying estimates of the impact of AI (Arntz et al. 2017; Acemoglu and Restrepo 2018), and uncertain macroeconomic futures, forecasting labour demand and wages is hazardous; and the uncertainty is raised further by the striking betweencountry variations manifested in recent years.

As a consequence, scholarly opinion about future prospects for graduates is divided between optimists who rest their beliefs on the persistent high value of the graduate wage premium in many countries for a long time, and pessimists who point to the seemingly high prevalence of graduate underemployment. Optimistic analysts can support their beliefs with forecasts of rising demands for creative and cognitive skills (Bakhshi and Yang 2015), but are less common on the ground in countries with a falling graduate wage premium; pessimists (for example, Holmes and Mayhew 2016; Mok 2016) highlight skills underutilisation and unemployment, college grade inflation and rising credentialism. In our view, a nuanced judgement is called for, in which both graduate excess supply data and wage trends are called on for a fuller ongoing understanding of trends. It is informative but not sufficient for policy-makers to rely on retrospective evidence on the wage premium to reveal important trends in graduate labour markets. There are complex, two-way links with unknown long-term lags between graduate wages and the supply/demand gaps, which are yet to be modelled adequately. The best understanding has to come from a holistic account of information in both the wages and occupational data that are consistently available over a long period of time. Our contribution in this paper is to utilise this available European data to analyse key trends over a medium-term period, which can be the basis for country-level analyses by policy-makers and researchers with access to more detailed information in particular countries.

Our findings do not reveal an optimistic picture regarding a convergence of national graduate labour markets across Europe. We confirm that there has been an ongoing upward convergence in the proportion of graduates in the workforce, and that this will probably continue in the present decade; yet there is no sign of upward convergence in the use of graduate labour in graduate jobs. Of course, the demarcation of graduate labour markets is not fully coterminous with national borders; yet the implications for European social cohesion of these labour markets converging only in terms of supply are uncertain. The findings are partly constrained, as noted above, by having to work with the major group 1-3 classification of graduate jobs as high-skilled jobs, in order to plot the decade-long changes. Repeated task-based data linked to occupations, consistent across countries and over time, would allow an analysis based on the alternative task-based classification method. When the countries that participated in the first and second rounds of the OECD's Survey of Adult Skills again join the planned next wave of surveys, there could be the opportunity to do this for the decade beginning in 2011. It must also be noted that estimates of wage premiums and wage penalties reported here cannot be treated as strictly causal estimates of treatment effects, either in the case of the decision to undertake tertiary education, or in the case of taking up employment in a non-graduate job: in both cases, to identify effects a causal estimator would require plausible, exogenous drivers, which are not available in these data. Finally, we have not examined here the variations in graduate unemployment.

Some general inferences may nevertheless be drawn for the formation of education policy, for the broader discourse on HE, and for research on graduate futures. Nation-wide policies to develop employability skills training in colleges and universities can improve equity and lower the costs of education to work transitions; access to good advice services retain an essential role in the promotion of opportunities for disadvantaged groups lacking established channels into rewarding graduate jobs. Moreover, better careers information and guidance systems in all universities will raise productivity if they improve the matches made between students' skills and employers' demands for skilled labour. However, these services should not be expected by policy-makers to carry the burden of upholding or framing the promise of employment in graduate jobs 
for modern-day students. For that, the key objective of a nation's policy should be to embed its tertiary education policies within an industrial strategy that is focused on promoting and incentivising increased levels of innovation. If the stimulation of innovation is successful, firms are likely to need graduate skills for the generation of new ideas, for effective further skill acquisition, for knowledge transfer, and for raising organisations' absorptive capacity to profitably utilise new technologies (Green and Mason 2015; Habibi 2019). Industrial policies that do not foster innovation are more likely to stimulate demand for less skilled labour. Such considerations would appear to apply with particular force in the eight countries we have identified as having experienced a particularly sharp rise in graduate underemployment: Slovenia, Slovakia, the Czech Republic, Poland, Italy and Greece.

Our findings on the diversity of trends in graduate labour markets imply a need for national policy-makers to monitor their graduate labour markets assiduously alongside their tertiary education policies; they should know where their supplies and their prospective demands for graduate labour are heading, and regularly survey graduates' wages; these data can then be used to inform prospective students, schools and colleges, all of whom must endeavour to make major long-term plans and decisions with considerable financial and lifechanging consequences as well as possible in an uncertain world.

Finally, it must be recalled that the value of tertiary education does not lie only in the private financial returns. There are partly-private non-financial benefits such as better health, and external benefits for society along with universities' public good aspects, which are quite separate from tertiary education's links with employment (McMahon 2009). Research shows that students are aware of non-financial benefits, even in contexts where the financial benefits remain of primary importance (Jonbekova 2019). External benefits are social and political as well as economic, and accrue irrespective of whether graduates are employed in graduate jobs (Marginson 2017; Green and Henseke 2016b). Considering their enormous policy relevance the comparative dearth of published research is striking. Notwithstanding the need to prepare students for employment, the broader purposes of tertiary education, then, ought to be included in considerations of education policy. And the monitoring of performance should therefore include the gathering of adequate intelligence surrounding the local and societal external benefits of tertiary education in each country.

Acknowledgements

Not applicable.

\section{Disclaimer}

This paper is based on EU-SILC and EU Labour Force Survey data, available on request from Eurostat. The responsibility for all conclusions drawn from the data lies entirely with the author(s).

\section{Authors' contributions}

The authors have made equal contributions. Both authors read and approved the final manuscript.

\section{Authors' information}

Francis Green is Professor of Work and Education Economics in UCL Institute of Education, where he works at the LLAKES Centre. After graduating in Physics at Oxford University, he studied Economics at the London School of Economics, before writing his Ph.D. thesis at Birkbeck College. His research focuses on education, skills, the graduate labour market and job quality.

Golo Henseke is Senior Research Associate (Applied Economist) at the UCL Institute of Education where he has worked since 2014. He works in two ESRC Research centres: the Centre for Learning and Life Chances (LLAKES) and the Centre for Global Higher Education. His research examines job quality, graduate labour markets and job transitions.

\section{Funding}

This study is supported by the Economic and Social Research Council, the Office for Students and Research England (Grant reference ES/M010082/1), and the Centre for Global Higher Education (CGHE), UCL Institute of Education, London.

\section{Availability of data and materials}

This paper is based on EU-SILC and EU Labour Force Survey data, available on request from Eurostat. The responsibility for all conclusions drawn from the data lies entirely with the authors.

\section{Ethics approval and consent to participate} Not applicable.

\section{Consent for publication}

Not applicable.

\section{Competing interests}

The authors declare that they have no competing interests.

Received: 8 September 2020 Accepted: 27 January 2021

Published online: 13 February 2021

\section{References}

Acemoglu, D., Restrepo, P.: Low-skill and high-skill automation. J. Hum. Cap. 12(2), 204-232 (2018)

Allen, J., van der Velden, R.: Educational mismatches versus skill mismatches: effects on wages, job satisfaction, and on-the-job search. Oxf. Econ. Pap. 53(3), 434-452 (2001)

Allen, J., Van der Velden, R.: The Flexible Professional in the Knowledge Society: New Challenges For Higher Education. Springer Science \& Business Media, Dordrecht (2011)

Almeida, A., Figueiredo, H., Portela, J.M., Sá C., Teixeira, P.: Returns to Postgraduate Education in Portugal: Holding on to a Higher Ground? GLO Discussion Paper, No. 44 (2017)

Altonji, J.G., Blom, E., Meghir, C.: Heterogeneity in Human Capital Investments: High School Curriculum, College Major, and Careers (No. w17985). National Bureau of Economic Research, Cambridge (2012)

Arntz, M., Gregory, T., Zierahn, U.: Revisiting the risk of automation. Econ. Lett. 159, 157-160 (2017)

Autor, D.H., Levy, F., Murnane, R.J.: The skill content of recent technological change: an empirical exploration. Q. J. Econ. 118(4), 1279-1333 (2003)

Baert, S., CockX, B., Verhaest, D.: Overeducation at the start of the career: stepping stone or trap? Labour Econ. 25, 123-140 (2013)

Bakhshi, H., Yang, L.: Creativity and the Future of Work. Fort Collins, NESTA (2015) 
Baran, J.: Is Expansion of Overeducation Cohort-Driven? Evidence from Poland. University of Warsaw, Faculty of Economic Sciences. Working Papers 13/2019 (298) (2019)

Barone, C., Ortiz, L.: Overeducation among European university graduates: a comparative analysis of its incidence and the importance of higher education differentiation. High. Educ. 61(3), 325-337 (2011)

Beaudry, P., Green, D.A., Sand, B.M.: The great reversal in the demand for skill and cognitive tasks. J. Labor Econ. 34(S1), S199-S247 (2016)

Blinder, A.S., Krueger, A.B.: Alternative measures of offshorability: a survey approach. J. Labor Econ. 31(2), S97-S128 (2013)

Boxall, P., Purcell, J.: Strategy and Human Resource Management, 3rd edn. Palgrave Macmillan, Basingstoke (2011)

British Academy and The Royal Society: The Impact of Artificial Intelligence on Work. British Academy and Royal Society, London (2018)

Brown, P., Hesketh, A., Williams, S.: The Mismanagement of Talent. Oxford University Press, Oxford (2004)

Crivellaro, E.:The college wage premium over time: trends in Europe in the last 15 years. In: Inequality: Causes and Consequences, pp. 287-328. Emerald Group Publishing Limited, Bingley (2016)

Elias, P., Purcell, K.: Classifying Graduate Occupations for the Knowledge Society. Futuretrack Working Paper, vol. 5, pp. 1-37 (2013)

Erez, M.: Culture and job design. J. Organ. Behav. 31(2-3), 389-400 (2010)

Eurofound: Convergence and Divergence of Working Conditions in Europe: 1990-2005. Office for Official Publications of the European Communities, Luxembourg (2009)

Eurofound: Drivers of Recent Job Polarisation and Upgrading in Europe: European Jobs Monitor 2014. Office for Official Publications of the European Communities, Luxembourg (2014)

Eurofound: Upward Convergence in Employment and Socioeconomic Factors. Publications Office of the European Union, Luxembourg (2019)

Figueiredo, H., Teixeira, P., Rubery, J.: Is Mass Higher Education Working? An Update and a Reflection on the Sustainability of Higher Education Expansion in Portugal. ALMALAUEA Working Papers, pp. 14 (2011)

Figueiredo, H., Teixeira, P., Rubery, J.: Unequal futures? Mass higher education and graduates' relative earnings in Portugal, 1995-2009. Appl. Econ. Lett. 20(10), 991-997 (2013)

Freeman, R.B.: The Overeducated American. Academic Press, New York (1976)

Gallie, D.: The quality of work in a changing labour market. Soc. Policy Adm. $\mathbf{5 1}(2), 226-243$ (2017)

Goos, M., Manning, A., Salomons, A.: Explaining job polarization: routine-biased technological change and offshoring. Am. Econ. Rev. 104(8), 2509-2526 (2014)

Green, F.: Skills and Skilled Work. An Economic and Social Analysis. Oxford University Press, Oxford (2013)

Green, F., Henseke, G.: The changing graduate labour market: analysis using a new indicator of graduate jobs. IZA J. Labor Policy 5(1), 14 (2016a)

Green, F., Henseke, G.: Should governments of OECD countries worry about graduate underemployment? Oxf. Rev. Econ. Policy 32(4), 514-537 (2016b)

Green, F., Mason, G.: Skills and training for a more innovation-intensive economy. In: Bailey, D., Cowling, K., Tomlinson, P. (eds.) New Perspectives on Industrial Policy for a Modern Britain. Oxford University Press, Oxford (2015)

Green, F., Mcintosh, S.: Is there a genuine underutilisation of skills amongst the over-qualified? Appl. Econ. 39(4), 427-439 (2007)

Green, F., Zhu, Y.: Overqualification, job dissatisfaction, and increasing dispersion in the returns to graduate education. Oxf. Econ. Pap. 62(4), 740-763 (2010)

Habibi, N.: Preventing overeducation and graduate surplus What can West Asia learn from Singapore and Hong Hong.' Asian Educ. Dev. Stud. 8(4), 523-535 (2019)
Henseke, G.: Against the grain? Assessing graduate labour market trends in Germany through a task-based indicator of graduate jobs. Soc Indic Res 141(2), 809-840 (2019)

Henseke, G., Green, F.: Cross-national deployment of "graduate jobs": analysis using a new indicator based on high skills use. In: Research in Labor Economics Skill Mismatch in Labour Markets, vol. 45, pp. 41-79. Bingley, Emerald Publishing Limited (2017)

Hoekstra, M.: The effect of attending the flagship state university on earnings: a discontinuity-based approach. Rev. Econ. Stat. 91(4), 717-724 (2009)

Holmes, C., Mayhew, K.:The economics of higher education. Oxf. Rev. Econ. Policy 32(4), 475-496 (2016)

Huang, L.H., Huang, H.Y.: Rigid low college premiums and the expansion of higher education in Taiwan. Singap. Econ. Rev. 60(4), 1550022 (2015)

ILO and OECD.: "The labour share in G20 economies". Report prepared for the G20 Employment Working Group Antalya, Turkey, 26-27 February. http:// www.oecd.org/g20/topics/employment-and-social-policy/The-Labou r-Share-in-G20-Economies.pdf (2015)

Iriondo, I., Pérez-Amaral, T.: The effect of educational mismatch on wages in Europe. J. Policy Model. 38(2), 304-323 (2016)

Jauhiainen, S.: Overeducation in the Finnish regional labour markets. Pap. Reg. Sci. 90(3), 573-588 (2011)

Jonbekova, D.: The diploma disease in Central Asia: students'views about purpose of university education in Kazakhstan and Tajikistan. Stud. High. Educ. (2019). https://doi.org/10.1080/03075079.2019.1628199

Kiersztyn, A.: Stuck in a mismatch? The persistence of overeducation during twenty years of the post-communist transition in Poland. Econ. Educ. Rev. 32, 78-91 (2013)

Korpi, T., Tahlin, M.: Educational mismatch, wages, and wage growth: overeducation in Sweden, 1974-2000. Labour Econ. 16(2), 183-193 (2009)

Lindley, J., Machin, S.: The rising postgraduate wage premium. Economica 83, 281-306 (2014)

Marginson, S.: High participation systems of higher education. J. High. Educ. $\mathbf{8 7}(2), 243-271$ (2016)

Marginson, $\mathrm{S}$.: The public good created by higher education institutions in Russia. VoprosyObrazovaniya-Educ. Stud. Mosc. 3, 8-36 (2017)

Martins, P.S., Pereira, P.T.: Does education reduce wage inequality? Quantile regression evidence from 16 countries. Labour Econ. 11(3), 355-371 (2004)

McMahon, W.W.: Higher Learning, Greater Good. The Private and Social Benefits of Higher Education. The Johns Hopkins University Press, Baltimore (2009)

Meroni, E.C., Vera-Toscano, E.: The persistence of overeducation among recent graduates. Labour Econ. 48, 120-143 (2017)

Mok, K.H.: Massification of higher education, graduate employment and social mobility in the Greater China region. Br. J. Sociol. Educ. 37(1), 51-71 (2016)

Rohrbach-Schmidt, D., Tiemann, M.: Mismatching and job tasks in Germanyrising over-qualification through polarization? Empir. Res. Vocat. Educ. Train. 3(1), 39-53 (2011)

Strawinski, P., Majchrowska, A., Broniatowska, P.: Wage returns to different education levels. Evidence from Poland. Ekonomista 2018(1), 25-49 (2018)

Verhaest, D., Van der Velden, R.: Cross-country differences in graduate overeducation. Eur. Sociol. Rev. 29(3), 642-653 (2013)

\section{Publisher's Note}

Springer Nature remains neutral with regard to jurisdictional claims in published maps and institutional affiliations. 